\title{
COVID-19-Some Lessons Identified
}

\section{Rostislav $\mathrm{K}^{*}$}

Department of Epidemiology and Disaster Medicine, Medical University Plovdiv, Bulgaria

*Corresponding author: Dr Rostislav Kostadinov, MD, PhD, DSc, Medical University Plovdiv, Public Health Faculty, Department "Epidemiology and Disaster Medicine, Bulgaria, Email: rostikosti@abv.bg

\section{Editorial}

Epidemics are accompanying the mankind from the very beginning of the human society development. It is extremely important to be noted that the biological damaging factor viruses, bacteria, fungi parasites and their toxins were and exist independently from human society with their potential to cause harm on human health or to threaten the life but in order epidemic to be declared it is a prerequisite some form of society existence. Only when a certain number of the population at risk are affected by the biological agent and this number is threatening the social activities and relations, only then an epidemic breakout could be declared. Nowadays within the disaster medicine community is widely accepted the concept that for a crisis or disaster development the human/society errors have to be traced as an origin. Even the pure "natural" disasters as an earthquake, flood or hurricane are classified as real disasters, when the required means and capabilities for inflicted by the damaging factors casualties and negative consequences to the infrastructure and environment are overwhelming the available at the moment and on the spot society capacities. Therefore, the epidemics, as crises or disasters, have to be analyzed as manmade (anthropogenic). The ongoing COVID-19 pandemic is exceptional evidence regarding the shortfalls into the crisis/ disaster planning and management activities [1,2].

The objective of this short review is to present some of the lessons identified throughout the last year related to the performed and unfortunately still ongoing planning, organizational and management activities for eradication of the pandemics caused by the novel SARS-CoV-2 virus. In order to achieve the set goal the means of descriptive and comparative methods were applied for analyzing the performed by the governments and healthcare services activities. Analyses from the performed research clearly are highlighting the significance of the disaster medical management education and training.
From the prehistoric times our predecessors empirically have found the basic rule into the biological area of damage management-if there are affected by the unknown disease, as were the majority of diseases into those years and centuries, they have to isolated from the other members of the society, in order not to spread the Devine wrath within all. Only few of the tribe was allowed to monitor and support the affected with the development of the science some of the diseases were exclude form the above-mentioned rule, because through the years a lot of observations have proved that they do not have a capacity to be transferred to those that are into contact with the diseased one. But the experience gained has clearly distinguished those symptoms and syndromes related to diseases that have a potential to easily and rapidly spread among all those that are close or around the affected, thus threatening the entire tribe/ society. A lot of speculations were made by the healthcare providers and governing authorities regarding the most probable source of such diseases-human sins, Divine will punishment for committed errors, destiny and etc. Notwithstanding, what reason for the disease appearance was accepted, the measures for preventing its devastating effects on an ordinary member and/or a society as whole, always have include restrictive approach - isolation or even abandoning the cursed area. Several glorious cities were left to oblivion only because of the touch of lethal hand of the disease. Moving ahead into the history and into the medical science development, piece by piece evidence regarding the epidemic diseases agent, sources and mode of transmission were identified, collected, analyzed and transformed into knowledge. The significance of the personal and social hygiene, the proper sanitation of the living areas, purity of the air, water sources and soil, the insects, animals and vegetations, the climate and environment were becoming evident and were considered as a required basis for assuring the population and society health and wellbeing into the 
Ancient world. The isolation of those infected into dedicated places for monitoring and treatment was a pillar into healthcare. What is more, the location dedicated for healing procedures were chosen $\mathrm{n}$ semi-remote areas in order to assure the peace, calm for the healing procedure, but also and isolation of those diseased from the other population. During the Middle Ages, characterized with some steps backwards from what was accepted as rules into sanitation, hygiene and healthcare provision in several areas, the approach to the epidemic diseases was not changed. Even without the scientific proofs, only based on the empirical gained data, the required measures for preventing the infectious diseases spread and development of epidemics and pandemics were imposed by all the available means - even with application of deadly force. A lot of military campaigns, even victories and defeats that have led to significant for the history outcomes were result of poorly or not managed epidemics among the ranks [3-5].

Closing of ports, routes, cities and even kingdoms were routine measures, along with the prays, benediction and punishment of the sinners and withes. Purification of the air, water clothes, homes, actively search and isolation of all with symptoms and those were in contact with them are just few of the measures through these centuries. The isolation of leprosy affected into certain villages, the restriction of their movement and contacts, the anti rodents activities, the use of boiling water and steam have entered into our textbooks from those time. The last century, characterized by world wars, extreme polarization of some societies and the unprecedented development of medicine as a whole and epidemiology, hygiene and social medicine in particular, has enriched both the theory and practice of epidemics and pandemics management. The lessons identified during Spanish flu pandemic were learnt and afterwards successfully implemented at end of century and into the beginning of the 21-st one (SARS, Avian Flu, Swine Flu, Measles, etc.)

Based on the acquired knowledge and practice, on the enhanced capabilities for identification, detection and eradication of the biological agents, the activities performed into the beginning and the passed one year of the COVID-19 pandemic are really surprising.

The following are just some observations on the exceptions of the epidemiological and disaster medicine best practice identified during the COVID-19 pandemic management $[6,7]$.

$>$ The most curious activities were performed into the very beginning of the pandemic. When Chinese health authorities declared the fast spread among the population of a new most probably airborne disease with proved human to human transmission and high contagiousness index, with unknown to the date virulence, but high drug resistance, requiring extraordinary treatment capacities, the only possible, proven through ages measure was the isolation. The movement restriction imposed, the full quarantine on tens of millions population could be only admired and taken as an example for adequate measures to novel biological threat. All what is described into the disaster medical management plans related to the population under quarantine and the required medical measures, as well those of the law-enforcement structures were followed and the result became evident within three months. All of the sudden, and opposing to all the regulation and a must activities in case of biological area of damage - no entry and no exit policy, several governments organized a flights to the affected area and have transported back to their countries their citizens that were living, working, duty travel, into the provinces under Chinese quarantine. These actions have violated the main, basic regulation of the biological area of damage management - not to permit spreading of the biological agent outside of the affected area. It was surprise to no one with epidemiological knowledge that after these flights the novel virus started its triumph march through the countries on all continents - from a regional one became a pandemic one.

$>$ Based on the fast spread of the infection and its modes of transmission the almost all countries reacted accordingly to what they have achieved - a global biological threat. After the first cases and understanding more about the virus characteristics, strict isolation measures were imposed, but unfortunately not the real required quarantine. Not imposing the quarantine was a little bit surprising based on the still poor results reported form the country first affected by the virus.

$>$ Achieving partial results in lowering the numbers of the newly infected, without eradicating the still existing biological threat, the majority of governments around the world lifted the lockdowns and millions of people went travelling for their holidays, thus providing new territories and new victims to the virus. The policy makers and medical authorities explained the decision with the better preparedness of the healthcare systems to react more adequately to the pandemic. From management point of view is always stated that it is better not to permit the crisis development instead to react to the consequences. But the result of this repeated approach is the second and third wave of the pandemic. When you are not focused on how to prevent the fire, but only on how to extinguish the flames, the outcomes of such an approach have to not surprise.

$>$ In every students textbook is highlighted that the better outcome of treatment is expected, when the patient is aware about why the treatment is required and what he/she has to do/not to do for supporting the healing process. What is observed even today-the population 
is receiving thousands of contradictory messages from medical professionals. Into the beginning there were messages that the novel virus is similar, even less harmful, to the seasonal flu, a huge discussion was ongoing all over the Medias regarding the face masks and social distancing, about the pros and cons of the regional, statewide or global lockdowns, about the freedom of movement, human rights and etc. There is nothing surprising after such a media campaign, that even nowadays with the above hundred millions infected and more than 2 millions fatalities, among the population is still not accepted by every citizen the need of the preventive and restrictive measures. Even we are observing a growing resistance against these measures. This ill communication could explain and the initial reluctance of the active immunizations recorded in several countries.

The objective of this short overview is to trigger a discussion among the medical community focused on the reasons of the above-mentioned and the several other decisions taken in contrary to the established practice. The desired result of these discussions is a clear vision, a strategy for better preparedness for mitigating the effects of the coming biological crises and disasters. In order words, not only to identify, but to learn lessons $[8,9]$.

\section{References}

1. Huremovic D (2019) Brief History of Pandemics (Pandemics Throughout History). Psychiatry of
Pandemics, pp: 7-35.

2. Hajar R (2012) The Air of history (Part II) medicine in the middle ages. Heart Views 13(4): 158-162.

3. Bell BP, Damon IK, Jernigan DB, Thomas AK, Stuart TN, et al. (2016) Overview, control strategies, and lessons learned in the cdc response to the 2014-2016 Ebola Epidemic. MMWR S65(3): 4-11.

4. Gates B (2015) The next epidemic-lessons from Ebola. N Engl J Med 372(15): 1381-1384.

5. Hoehl S, Rabenau H, Berger A, Marhild K, Jindrich C, et al. (2020) Evidence of SARS-CoV-2 infection in returning travelers from Wuhan, China. N Engl J Med 382: 12781280.

6. Frieden TR, Tappero JW, Dowell SF, Nguyen TH, Florence DG, et al. (2014) Safer countries through global health security. Lancet 383(9919): 764-766.

7. Kostadinov R (2018) Disaster Medicine Highlights, Plovdiv, Lax book.

8. Gregory C, Philip A, Erik ADH, Robert D, Irving J, et al. (2006) Ciottone's Disaster Medicine. Elsevier Health Sciences.

9. Daszak P, Olival KJ, Hongying L (2020) A strategy to prevent future epidemics similar to the 2019-nCoV outbreak. Biosaf Health 2(1): 6-8. 